\title{
Design of Efficient Power Supply for the Proper Operation of Bio-Mimetic Soft Lens
}

\author{
Saad Hayat $^{1}$
FET, Gomal University
Dera Ismail Khan, Pakistan \\ Saad Hayat $^{1}$
FET, Gomal University
Dera Ismail Khan, Pakistan \\ Saad Hayat ${ }^{1}$
FET, Gomal University
Dera Ismail Khan, Pakistan
}

\author{
Muhammad Salman Khan ${ }^{5}$ \\ FET, Gomal University \\ Dera Ismail Khan, Pakistan
}

Sheeraz Ahmed
Iqra National University
Peshawar, Pakistan

Malik Shah Zeb Ali ${ }^{3}$

FET, Gomal University

Dera Ismail Khan, Pakistan

\author{
Muhammad Usama ${ }^{6}$ \\ FET, Gomal University \\ Dera Ismail Khan, Pakistan
}

\author{
Muhammad Qaiser Khan ${ }^{4}$ \\ FET, Gomal University \\ Dera Ismail Khan, Pakistan
}

\author{
Zeeshan Najam ${ }^{7}$ \\ Deptt of Electrical Engineering \\ MNS UET Multan, Pakistan
}

\author{
Asif Nawaz ${ }^{8}$ \\ Faculty of Engineering (Electronics) \\ Higher College of Technology, Dubai, UAE
}

\begin{abstract}
Soft Robotics is one of the emerging and topnotched researched fields in Robotics which collaborate and Interact with Human Machine Interface (HMI). Several power electronics and electrical devices are used for the proper operation of these robots, among them high voltage power supply plays a vital role. Several approaches are used for the design of the high voltage power supply but still there is a deficiency in the design of the power supply which fulfill our desires level (highly efficient and less complex). This paper presents the efficient power supply for the control of bio-mimetic lens. The proposed power supply is designed by the use of boost converter, single phase inverter and the cock-croft Walton Voltage Multiplier. The work employs the use of power electronics for the achievement of the efficient high voltage power supply and boost the level of voltage up to 5 $k V$. Numerical simulations are performed for the comprehensive testing of the proposed model. Simulink is used for designing of the high voltage supply for simulation work. More-over the results are verified with the designing of laboratory setup. The experimental results are close to the simulation results with an error less than $3 \%$. This proof the validity of proposed high voltage power supply.
\end{abstract}

Keywords-Cock croft walton multiplier; EOG; elastomers; bio mimetic lens; template

\section{INTRODUCTION}

High voltage plays an important role in the field of energy optimization, power electronics and plays a promising role in field of robotics. Robots have penetrated every corner of our daily life and legitimizing every aspect of it. The field of robotics have reinforced our will to achieve targets which were previously hard to achieve. Several kinds of robots are present like work assisting robots, Social robots, floor cleaning robot and window cleaning robot [1]. A new generation of robots is taking place over rigid robots termed as Soft Robots. Soft robots have been materialized by a hefty margin in last years. These robots encouraged by the essence of human bones and tissues are exceptionally manipulative and offer high rate of mobility as compared to anticipated hard robots which are made up of rigid materials [2],[3].
The kind of soft robot unto which this research is based upon is soft lens or robotic lens. Soft lens provides human to machine interface and falls under the category of tunable optical component [4]. The actuation in the soft lens is manipulated by the use of EOG signals. Since EOG signals are in order of milli-volts. The dielectric elastomers (DE-As) are used in the soft robotics for the conversion of the electrical energy into mechanical energy by producing the large strains [5]. High voltage is required for the proper operation of the DE-As [23]. The robots using elastomers require the use of the $\mathrm{DC}$ to DC converter for of the high potential requirements. The direction of the research is on the design of the efficient power supply for the proper operation of soft robots [6].

In the previous studies the high voltage power supply has been designed by using different power electronic techniques[24],[25]. The design of efficient high voltage power supply requires enough time and money. In one research the use of transformer is made for the achievement of the high voltage [7]. The transformer used in this case is step up transformer. The use of transformers is not suitable for the field of robotics and in case of advanced research in electrical and electronics engineering. Moreover, the losses in transformer increases its limitations for the use in power supply. Saturation of the transformer leads to the distortions in the secondary side during short circuit. Moreover with this saturation the failure of the protection system occur and this leads to the system failure in severe cases. One of the major limitation of the use of transformer is its poor response during high frequency cases [8],[9],[10]. As the use of transformer makes circuit bulky, increase distortion in input current and increases power dissipation, therefore its use is limited to conventional linear power supply. In order to mitigate the limitations in the conventional linear power supply the use of the of the high frequency switching technique has been used by one group. They proposed by minimized circuit containing the boost converters. The boost circuit step up the level of the DC voltage with the use of the inductor, capacitor and the transistor [11]. In another the research the use of the two boost PFC (power factor corrector) converters are used for the 
achievement of the high voltage with higher efficiency. The use of the adaptive technique is made for maintaining the output voltage at desired level [12]. The limitation with this approach is the switching noise and the losses due to use of transistor at high voltage level. In order to overcome the limitations with boost converters, cock croft multiplier technique is proposed by one group. This circuit used the number of the capacitors for the achievement of high voltage. Voltage multiplier circuits are used primarily to develop high voltages where low current is required. The Voltage multiplier circuit which has the ratio of output voltage to input voltage depending on number of stages [13],[14].

This paper presents a precious approach for designing of efficient power supply to control the operations of bio mimetic soft lens. The proposed power supply consist of three main parts for achieving the high voltage and goal behind this division is to mitigate the limitations of previous approaches. Among the three parts (boost circuit, inverter circuit and the cock-croft) cock-croft Walton voltage multiplier circuit plays a vital role. This method works by taking the small input voltage and boost them to higher level with higher efficiency in order to control the lens. The model has been designed on MATLAB software and the verification of the methodology has been carried out in the laboratory environment.

The proposed work is categorized into following sections. In Section II mathematical modeling of the proposed system has been carried out. Section III shows the methodology of the presented power supply and the numerical simulations are presented in Section IV. Further the laboratory setup and the conclusion are explained in Sections V and VI.

\section{A. Mathematical Modeling}

The proposed method is based on the mathematical modeling of the booster circuit, inverter circuit and the cock-croft walton multiplier.

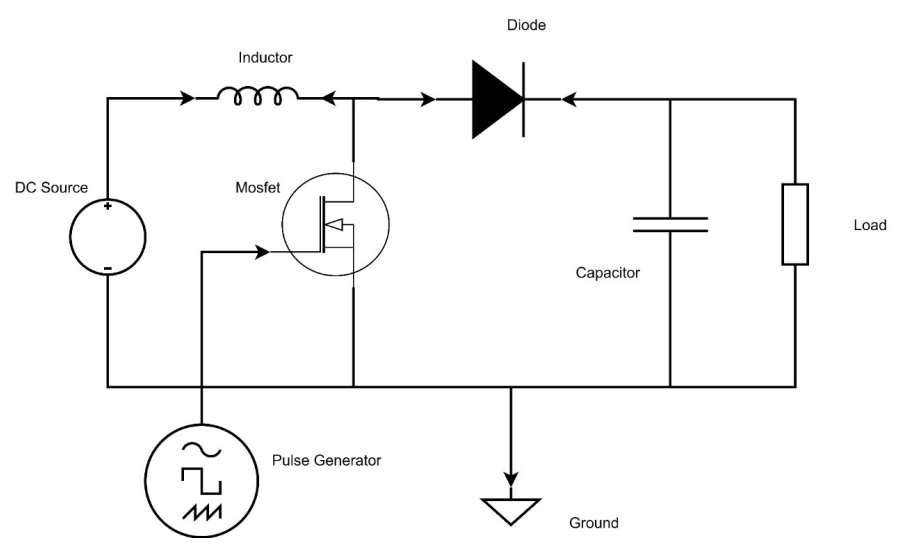

Fig. 1. Boost Converter System

1) Boost converter: In boost converter usually the output voltage are greater than the applied voltage. Turning on the controlled switch, the current flow through the inductor and it stores the energy as shown in Fig. 1. The storage of current charge results in the magnetization of inductor and when the switch is turned off, the current flow across the inductor shifts towards zero and results in demagnetization of inductor. The inductor now acts as voltage source to provide the sufficient voltage to the circuit by the reverse in its polarity. The voltage across the inductor and the applied voltage together charge the output capacitor placed across the load with a voltage higher than the input voltage and results in the boost of the voltage. Due to operation in CCM (continuous conduction mode) the current never drops to zero [15].

The boost converter follows two state operation, open or closed. When switch is closed, the current flow across the inductor and rise the clock pulse and in open state the reverse operation exist. When the controlled switch is in on state [16]:

$$
\begin{gathered}
\frac{d_{i}}{d_{t}}=\left(\frac{V_{i_{n}}}{L}-\frac{r_{i}}{L}\right) * I \\
\frac{d_{v_{c}}}{d_{t}}=\frac{V_{c}}{C} *\left(R+r_{c}\right)
\end{gathered}
$$

During the off state the mathematical equations becomes

$$
\begin{gathered}
\frac{d_{i}}{d_{t}}=\left(\frac{V_{i_{n}}}{\frac{L-I}{L}}\right) *\left(\frac{r_{l}+R_{r_{c}}}{R+r_{c}}\right)-\left(v_{c} * \frac{R}{L} *\left(R+r_{c}\right)\right) \\
\frac{d_{v_{c}}}{d_{t}}=\frac{1}{C}\left(R+r_{c}\right) *\left(R_{i}-r_{c}\right)
\end{gathered}
$$

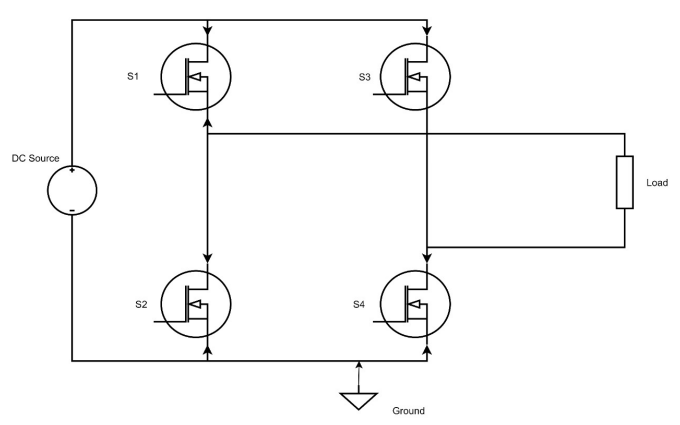

Fig. 2. Inverter Model

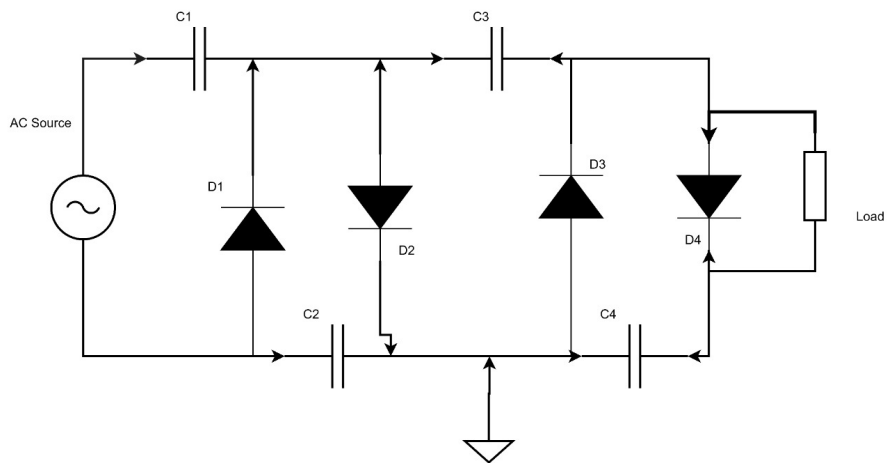

Fig. 3. Cock-croft Walton Multiplier 
2) Inverter: Inverter is the device used for the conversion of the DC voltage into AC, its circuit diagram is shown if Fig. 2. The switching frequency of the inverter can be written as [17].

$$
\text { Frequency }=f_{o}=\frac{1}{2} * \pi * R * C
$$

3) Cock croft Walton Voltage Multiplier: The peak surge current rating of the mostly rectifier diode has to be assigned with respect to the input voltage rating, shown in Fig. 3. In this work the peak surge current is one of the main factor to in dose the persistence would be the selection of diode. It might be the rectifier diode combination are more important is to control the forward surge current corresponding to the large capacitive loading effect. The surge current might have not damage the appearance of capacitor at the load. The load current are the limiting factor to maintain the overall consistency of diode working [18]. For the n-stage of the rectifier diode circuit is associated to develop the load due to the large rating of capacitor and the capacitive loading effect are the main reason is to establish them selves the diode set up in the cascade system of component. Here number of stages has to be increase the forward surge current are developed at the load greater the number of capacitor larger will be the total capacitance which should be obtained during the experimental setup and can be expressed as [19],[20].

$$
\begin{gathered}
C^{\prime}=n C_{1} \\
n=\frac{N_{2}}{N_{1}} \\
C=\frac{V_{p_{e_{k}}}}{R_{s}}=\sqrt{2} \frac{V_{R_{M_{S}}}}{R_{s}}
\end{gathered}
$$

Forward voltage drop is given as

$$
V_{f_{d}}=\frac{I_{l_{o_{d}}}}{6 f C}\left(n^{3}+2 n\right)
$$

Whenever high voltage generating circuit is loaded, a fluctuation in the output DC voltage $\delta V$ appears, which depends on the supply and frequency is known as ripple.

$$
\delta V=I_{f}\left(1 C_{n}+2 C_{n_{-1}}+\ldots . .+n C_{1}\right)
$$

From above equation it is shows, in multiplier circuit a low voltage rating capacitors are responsible for most ripple. Therefore, capacitors of different values are calculate in practical circuits and the ripple for circuit is given as

$$
\delta V=\operatorname{IfCn}(n+1)^{2}
$$

This quantity is to be evaluated is the voltage drop Vd across each stage and also calculated the overall voltage in regular manner. That make feel a difference of practical approach over the theoretical way no load voltage $2 \mathrm{nVmax}$ and the on load voltage

$$
\begin{aligned}
& V_{d}=\frac{I}{f C}\left(\frac{2}{3} n^{3}+\frac{1}{2} n^{2}-\frac{1}{6} n\right) \\
& \text { Voltageregulation }=\frac{V}{2 n E m}
\end{aligned}
$$

\section{Method FOR The Design Of EFFICIENT High Voltage POWER SUPPly}

The proposed method is based on the design of the efficient power supply for the generation of high voltage. The power supply working methodology is discussed in the three parts. The method starts with the working of boost converter, working of inverter comes after the boost converter. The method presented in this work ends with the use of the cock-croft walton multiplier. The boost converter is used for the increase in the level of the voltage up to desired state. In this work the major focus is on the states occurred during switching mode. One is the continuous conduction mode (CCM) and the other is the Discontinuous conduction mode and in this case conditions are made to operate our sytem in (CCM) and to avoid the operation in (DCM). The feedback mechanism has been used to maintain the output DC Voltage at specific frequency level $(2.4 \mathrm{kHz})$ obtained by considering the design parameters of converter. Boost converter has two states with respect to the time and flow of current across the conductor changes with the change in the polarity. Charging and discharging of the inductor increase the voltage level and it is made possible by controlling the switch (MOSFET). The control of switching frequency is made possible through the driver circuits operates on the pulses (PWM) from Arduino. The booster in this work takes $5 \mathrm{~V}$ at the input terminal boost them to $12 \mathrm{~V}$ and control them at desired level (12 V). An opto-coupler (4N28) has been used to control the feedback loop. The Single phase pure sine

TABle I. Boost Converter Model Parameters

\begin{tabular}{||c||c||}
\hline \hline Equipment & Values \\
\hline \hline Capacitor & $33 \mathrm{uF}$ \\
Inductor & $9 \mathrm{mH}$ \\
MOSFET & $2.4 \mathrm{KHz}$ (switching) \\
Load Resistance & $60 \mathrm{ohm}$ \\
\hline \hline
\end{tabular}

wave DC-AC inverter is the second part of an efficient power supply. It consists of $\mathrm{H}$-bridge and a step-up transformer. $\mathrm{H}$ bridge is the main operating part of the inverter which converts the DC input into AC output. The conversion takes place through proper switching with the use of MOSFET. The HBridge contains a series of four controllable switches in which there are two sets of two switches. One set of switches when closed allows electricity to flow in one direction and the other set allows electricity to flow in the opposite direction. The LC Filter is used to remove the extra spikes and results in pure sinusoidal AC output. Two types of losses occurs in the inverter used in this work, one is electromagnetic interference which exists due to the fast change in the polarity. This loss results in the damage of inverter. The second loss occur when the spike of voltage is more than the system can tolerate. Significant or sometimes catastrophic damage to the device itself caused by this loss. In case of protection from these losses snubbers are used to limitize the level of losses and rescue the device from the internal damage. Moreover it reduces the voltage transients in the electric system. RC snubbers are typically used before the $\mathrm{H}$ - Bridge to control the sudden voltage spikes occur and diode snubbers are used to control the output current flow to protect electronics components placed inside the inverter. The inverter converts the $12 \mathrm{~V} \mathrm{DC}$ to $12 \mathrm{~V} \mathrm{AC}$ and with the use of 


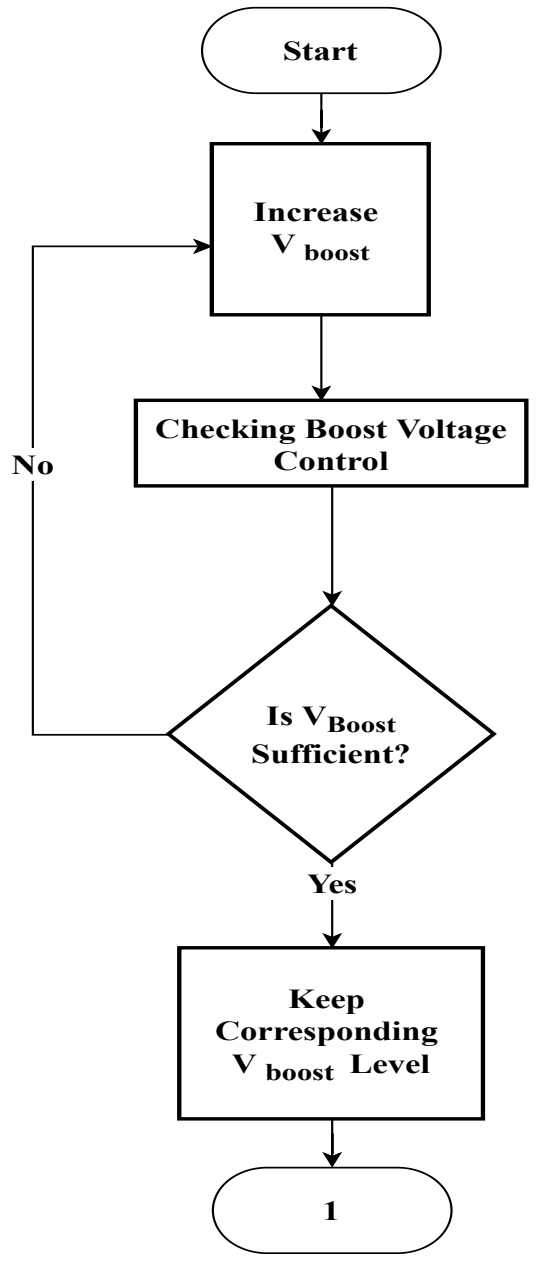

(a)

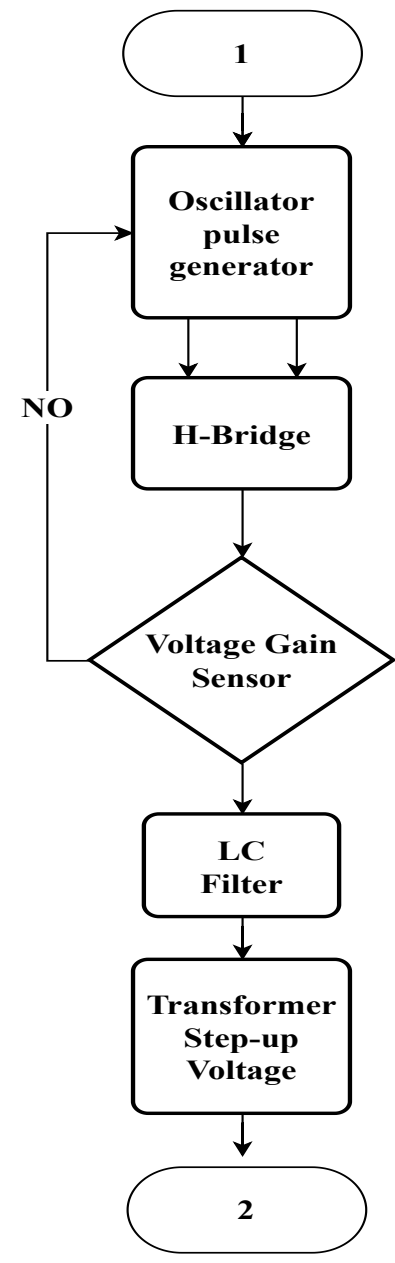

(b)

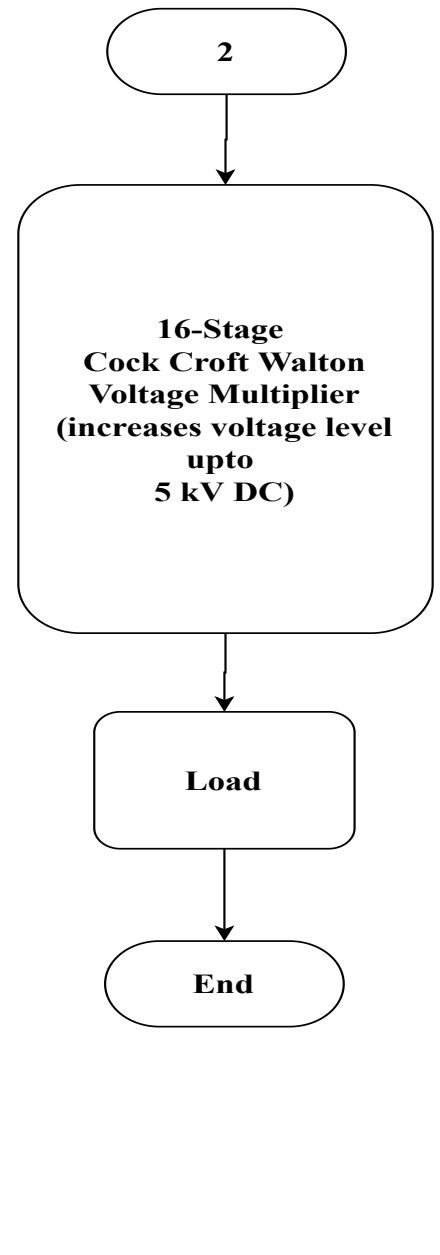

(c)

Fig. 4. Proposed Methodology (a) Boost Converter (b) Inverter (c) Cock croft Multiplier

transformer the $12 \mathrm{~V}$ AC is converted into $320 \mathrm{~V}$ AC. These voltages are moved towards the last stage of power supply. Cock-croft walton voltage multiplier is the third stage and main part of our high voltage power supply. It consists of a cascade or multiplier circuit and the devices are arranged in the ladder form. The increase in voltage has been made stage by stage with the use of the rectifier circuit. In rectifier circuit the diodes and capacitors are placed parallel to each other. The main objective behind the use of multiplier circuit is to increase the level of input voltage by adding the stages of rectifier circuit. As the capacitor store the charge to some extent and increase the voltages stage by stage to several $\mathrm{kV}$, with the constant voltage drop across each stage. The main focus is to maintain the load impedance with a constant voltage drop at each stage. The output current rating is in milli-ampere to avoid any damage to the electronics component or complete device. The voltage multiplier is easy to design but the selection of components is very difficult. To understand that the selection of capacitors and diodes are based on different parameters. The input frequency is the main reason for the selection of these electronics components. With the use of the cock croft walton voltage multiplier, we are able to obtain the desired level of voltage $(5 \mathrm{kV})$ by increasing the level from $320 \mathrm{~V}$ AC to 5 KV DC. The whole methodology is shown in Fig. 4.

TABLE II. INVERTER MOdel PARAMETERS

\begin{tabular}{||c||c||}
\hline \hline Equipment & Values \\
\hline \hline Snubber Resistance (Rs) & $660 \mathrm{ohm}$ \\
Snubber Capacitance (Cs) & $1 \mathrm{nF}$ \\
MOSFET & $50 \mathrm{~Hz}$ (switching) \\
Load Resistance & $150 \mathrm{ohm}$ \\
Low Pass filter & $\mathrm{L}=0.5 \mathrm{H}, \mathrm{C}=33 \mathrm{uF}$ \\
\hline \hline
\end{tabular}

\section{NUMERICAL SimUlations}

This paper presents the efficient high voltage power supply for the tun-able soft lens. The High voltage power supply consist of various power electronics applications that utilize to build a high voltage power supply. Simulink is used for the modeling of power supply and the model starts with the 


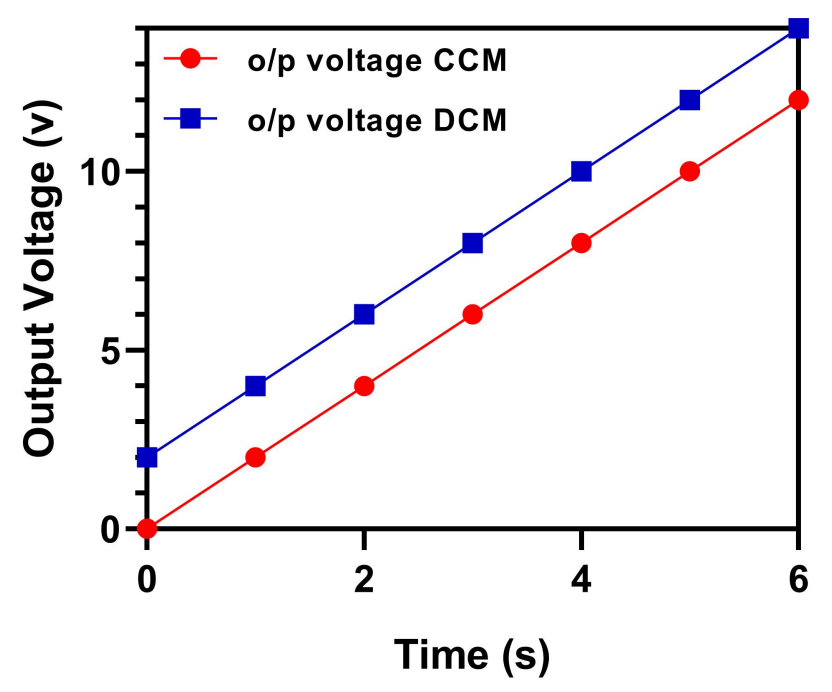

Fig. 5. Boost Converter Operation in CCM and DCM

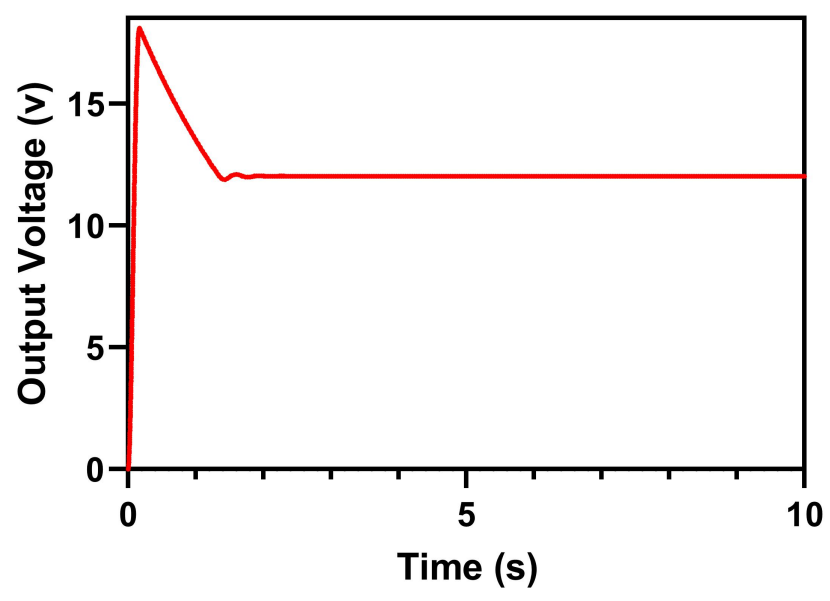

Fig. 6. Boost Converter Operation

designing of boost converter. The parameters used for the designing of boost converter are shown in Table I.

Fig. 5 show boost converter operation in continuous conduction mode (CCM) and discontinuous conduction mode (DCM). The output voltage rises constantly for time and the load current shall remain the same during CCM. In DCM the output voltage changes its position and variate from different point to point connection. In this method the boost converter operates in CCM and plays an important role for step up the low input DC voltage to desired continuous DC output Voltage. In real time scenario the inductor current never falls to zero and stay modulated in the positive side. Boost converter can step up the $5 \mathrm{v}$ input to $12 \mathrm{v}$ output with operation in CCM as shown in Fig. 6. A feedback mechanism maintain the output voltage in the CCM and perform the stepping action. The output load are the main part of boost converter as it decide the switching modes whether it can be in CCM or DCM. The load impedance could match according to the capacitor placed parallel to the output load. Moreover the output voltage ripple is $5 \%$ and the inductor current ripple is $20 \%$. The second part of the high voltage power supply is the pure sine wave single phase inverter. In Simulink, this block of single-phase inverter produced $\mathrm{AC}$ output from the Continuous DC input. The inverter can convert the DC input of $12 \mathrm{v}$ into $12 \mathrm{v}$ AC by proper switching of high voltage MOSFET using the H-bridge arrangement. The parameters of inverter are shown in Table II.

Inverter consist of Two pairs of two fast switching MOSFET which can convert DC into Square wave output as shown in Fig. 8. Te use of low pass filter has been made for obtaining the sinusoidal wave from the square wave as shown in Fig. 9. The transformer is used with the inverter for increasing the voltage level to $320 \mathrm{~V}$. The parameters of transformers are shown in Table III. The output obtained after amplification from transformer is shown in Fig. 10. Cock-croft Walton

TABLE III. SteP UP TRANSFORMer PARAMETERS

\begin{tabular}{||c||c||}
\hline \hline Equipment & Values \\
\hline \hline Power & $250 \mathrm{kV}$ \\
Frequency & $50 \mathrm{~Hz}$ \\
Input & $12 \mathrm{~V}$ \\
Output & $320 \mathrm{~V}$ \\
\hline \hline
\end{tabular}

voltage multiplier circuit consist of ladder arrangement of the capacitor and diodes. Capacitors and diodes are chosen based on the input voltage and the suitable parameters of previous blocks of the boost converter and the single-phase inverter with step-up Transformer. For the selection of the capacitor and diode depends upon the frequency of the input voltage. The range of capacitor is $0.2 \mathrm{mF}$ to $0.4 \mathrm{mF}$ the output voltage ripple would be the $5 \%$ of the output voltage. The parameters of Cock-croft Walton is shown in Table IV. The CWM increases

TABLE IV. CWM PARAMETERS

\begin{tabular}{||c||c||}
\hline \hline Equipment & Values \\
\hline \hline Capacitor & $470 \mathrm{uF}$ \\
Load resistor & $1 \mathrm{Mega} \mathrm{ohm}$ \\
Input & $320 \mathrm{~V}$ \\
Output & $5000 \mathrm{~V}$ \\
Output voltage ripple & $5 \%$ \\
\hline \hline
\end{tabular}

the voltage level to near about $5 \mathrm{kV}$, as per requirement for the operation of control of lens. The step wise increase in the level of the voltage with each stage is shown in Fig. 11 and whole circuitry designed in Simulink is shown in Fig. 7.

\section{EXPERIMENTAL SETUP}

Experimental set up has divided into three main stages, boost converter inverter and cock-croft Walton voltage multiplier. Boost converter is designed with the used of the bread board and the wires by connecting the electronics devices and 


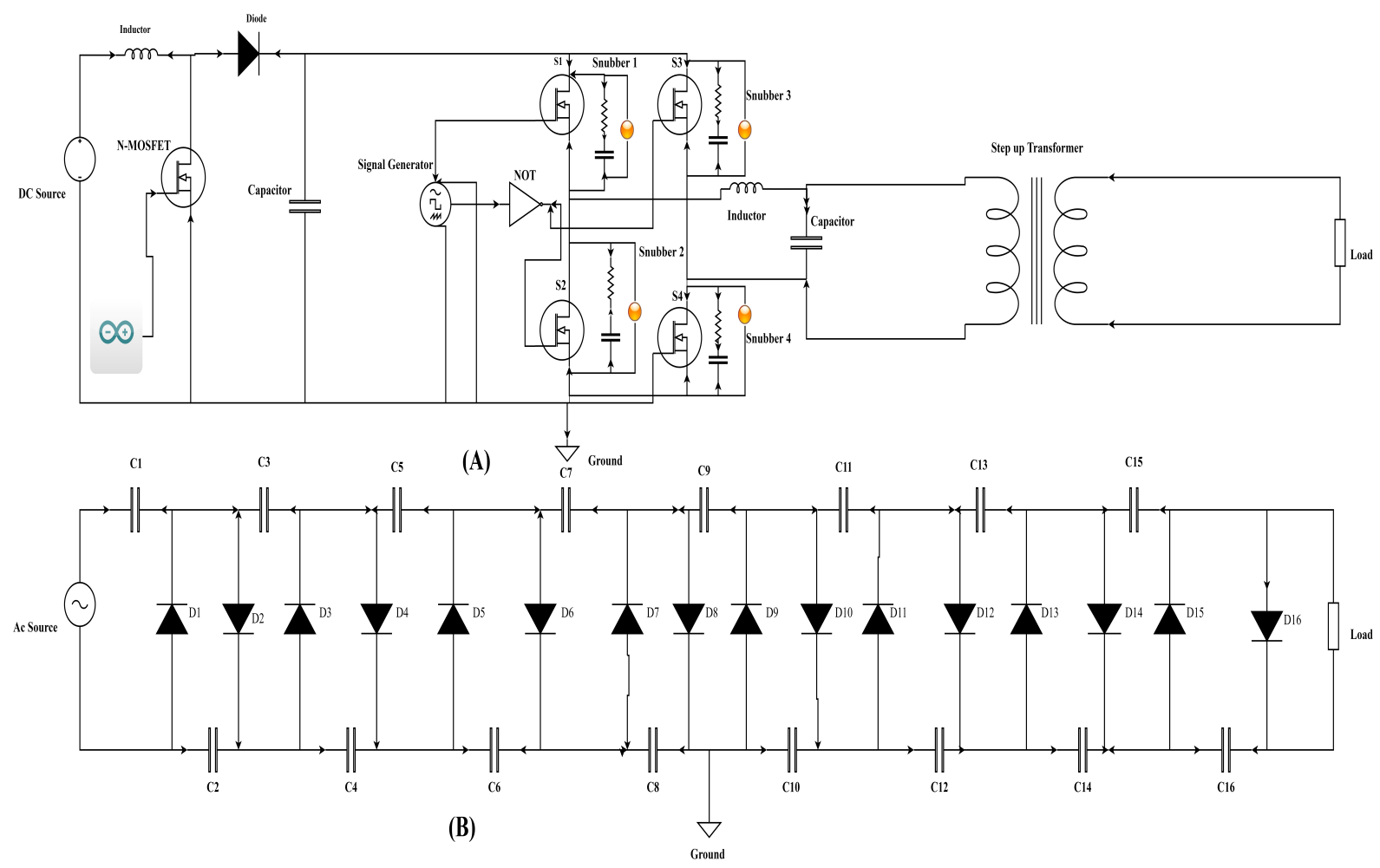

Fig. 7. Complete Circuitry of Power Supply (A) Boost Converter and Inverter (B) Cock croft Multiplier

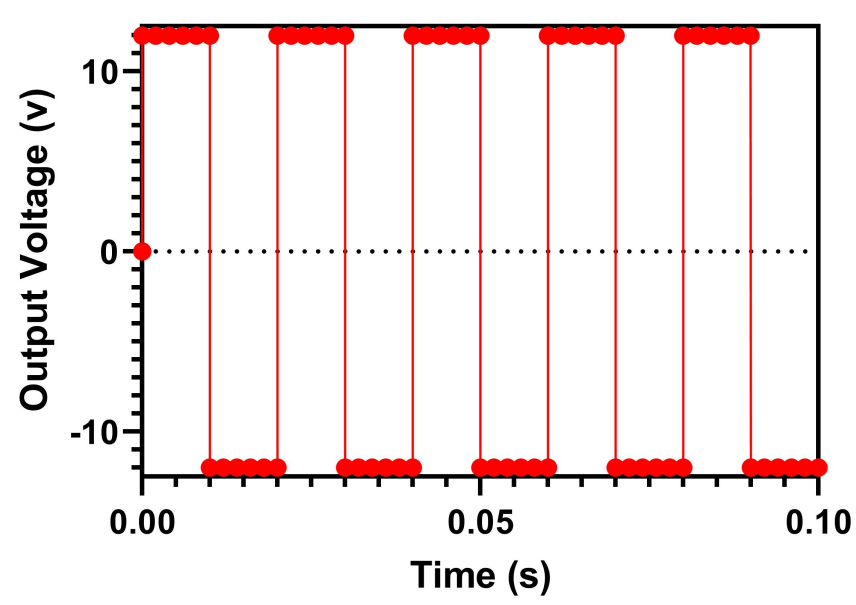

Fig. 8. Square Wave

the controller with low voltage power supply. Pulse Width Modulation(PWM) is used with the help of controller to run the gate of N-channel power MOSFET (IRF-540), low voltage inductor of $10 \mathrm{mH}$, power diode (2N2222), Ceramic capacitor of $33 \mathrm{uF}$ with low ESR and an opto coupler for reference voltage in close loop is used for increasing the voltage level from 5 A to $12 \mathrm{~V}$ DC. Moreover a digital multimeter and oscilloscope for data acquisition. All these electronic component placed and connect on breadboard and observe the output result. The experimental setup for the design of boost

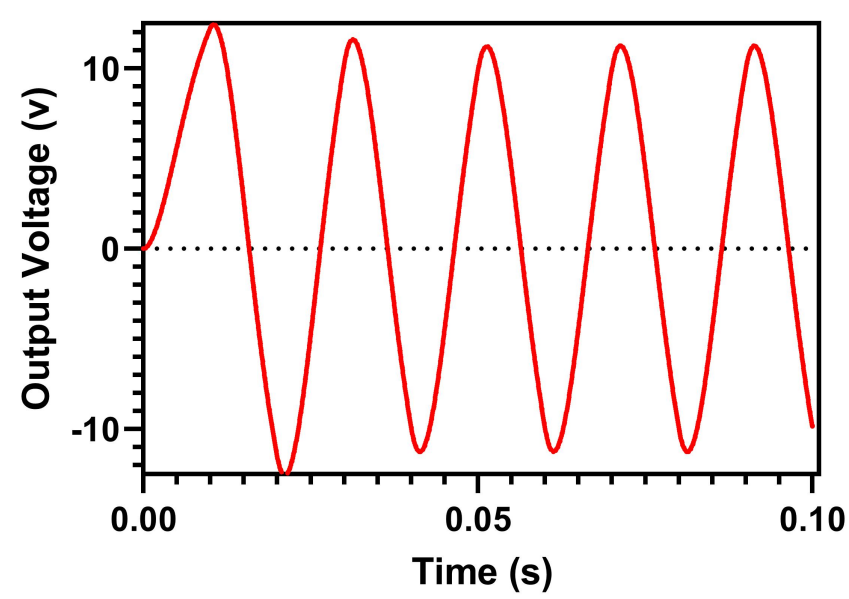

Fig. 9. Pure Sine Wave Results

converter is shown in Fig. 12.

Inverter is used for the conversion of $\mathrm{DC}$ to $\mathrm{AC}$ and transformer boosts the level of the voltage from the $12 \mathrm{~V}$ AC to the $320 \mathrm{~V}$ AC. Cock-Croft Walton Multiplier circuit works after the generation of $320 \mathrm{~V} \mathrm{AC}$ and is a cascade system with ladder arrangement of capacitor and diode which can be placed on breadboard in parallel arrangement. A multiplier circuit consist of two types of capacitors through which increase in the voltage level stage by stage obtained with different intensity of spark at the output. The intensity of spark is 


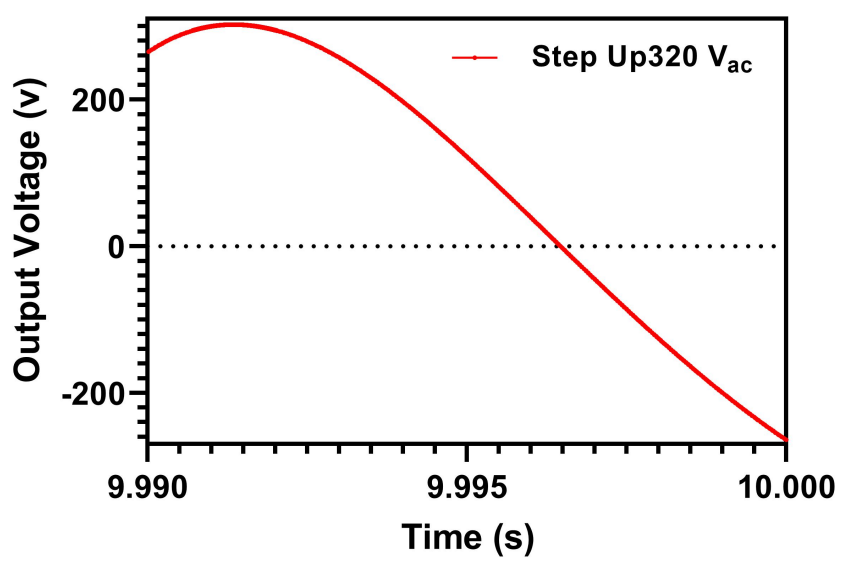

Fig. 10. Step up Transformer Result

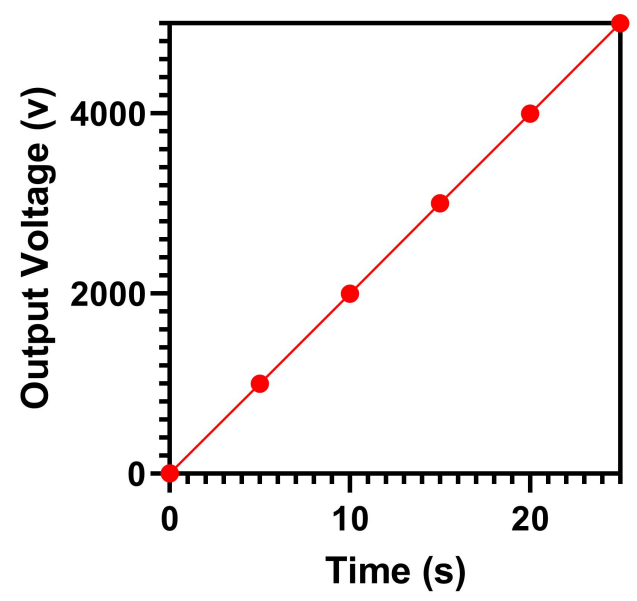

Fig. 11. CWM Results

directly proportional to the distance for which the spark has generated and the distance of spark would be the $10 \mathrm{~mm}$ of 5 $\mathrm{kV}$ high voltage. Two types of capacitor has been used in this experiment for increasing the level of voltage, one is polyester sheet capacitor $(2.2 \mathrm{nF})$ and the other is ceramic capacitor $(470$ $\mathrm{uF})$.

\section{A. Experiment using Polyester Capacitor}

Polyester sheet capacitor is a high voltage rating capacitor and it is used in high voltage power supply to store the charge stage by stage. Film (polyester) capacitor are used for the high frequency power application as they maintain the temperature to save the device. High voltage probe has been used for further modification and obtained the best results for the operation of soft lens as a capacitive loading effect. The experimental setup has been shown in Fig. 13 [21].

\section{B. Experiment using Ceramic Capacitor}

The ceramic capacitor have high voltage rating and it operates at low frequency of input line voltage. The ceramic capacitor charging and discharging rate are very slow and it takes a while to store the charge and boost up the input voltage stage by stage. Its Equivalent series resistance is very low and the voltage drop across each side is different with respect to the rate of charging and discharging. While air space would be the very good insulator which can either stop the spark. The voltage rating of ceramic capacitor depends upon the nature of load and the value of capacitor depends upon the input switching frequency of applied voltage. The voltage rating of capacitor is $470 \mathrm{uF}$ and $6000 \mathrm{v}$ threshold voltage [22]. High voltage diode which allow or block the voltage. It is very important to maintain the polarity of capacitor when source reverses its polarity. The forward voltage drop is $0.7 \mathrm{v}$ and the output voltage ripple is $5 \%$. The experimental setup using ceramic capacitor is shown in Fig. 14. The spark of film capacitor is greater than the ceramic capacitor to achieve desired level of voltage. The use of CWM allow us to generate nearly about $5 \mathrm{kV}$ and the results are closely related to the simulation work results.

\section{CONCLUSion}

This work employs design of an efficient power supply for the proper operation of bio mimetic soft lens. The proposed high voltage power supply plays a vital role inn the field of power electronics and soft robotics .Designing of Boost converter and Cock-Croft Walton Multiplier are the main parts of efficient power supply. Boost converter has been designed under the continuous conduction mode and step up voltage $5 \mathrm{v}$ to $12 \mathrm{v}$ with the promising output conditions. The linear behavior of boost converter is to maintain the DC level at the output. Cock-croft Walton Voltage multiplier circuit is used to attain a high output voltage with low output current. The Cock-croft Walton Voltage multiplier circuit plays an Important role in the emerging field of power electronics and it works by taking a very low AC input voltage boost up stage by stage to the higher level with greater efficiency. In order to control the basic operation of soft lens $5 \mathrm{kV}$ output DC voltage has been required which would be obtained by this multiplier circuit. This model has been designed in MATLAB (Simulink) for the simulation and numerical analysis and the practical verification of this model has been carried out in the laboratory environment. The result of numerical simulation and the laboratory model are closely related to each other with the error less than $3 \%$.

\section{REFERENCES}

[1] Coviello, L., et al. "Machine Learning based Physical Human-Robot Interaction for Walking Support of Frail People.” 2019 41st Annual International Conference of the IEEE Engineering in Medicine and Biology Society (EMBC). IEEE, 2019

[2] Iwasaki, Yukiko, Kota Gushima, and Emi Tamaki. "Interaction with the Mercurial Robot: Work Assisting Robot Express the Tiredness." Proceedings of the 2019 2nd International Conference on Electronics, Communications and Control Engineering. 2019.

[3] Shelton IV, Frederick E., and Jason L. Harris. "Cooperative surgical actions for robot-assisted surgical platforms." U.S. Patent Application No. $15 / 940,683$.

[4] Li, Jinrong, et al. "A Biomimetic Soft Lens Controlled by Electrooculographic Signal." Advanced Functional Materials 29.36 (2019): 1903762

[5] Gupta, Ujjaval, et al. "Soft robots based on dielectric elastomer actuators: a review." Smart Materials and Structures 28.10 (2019): 103002. 

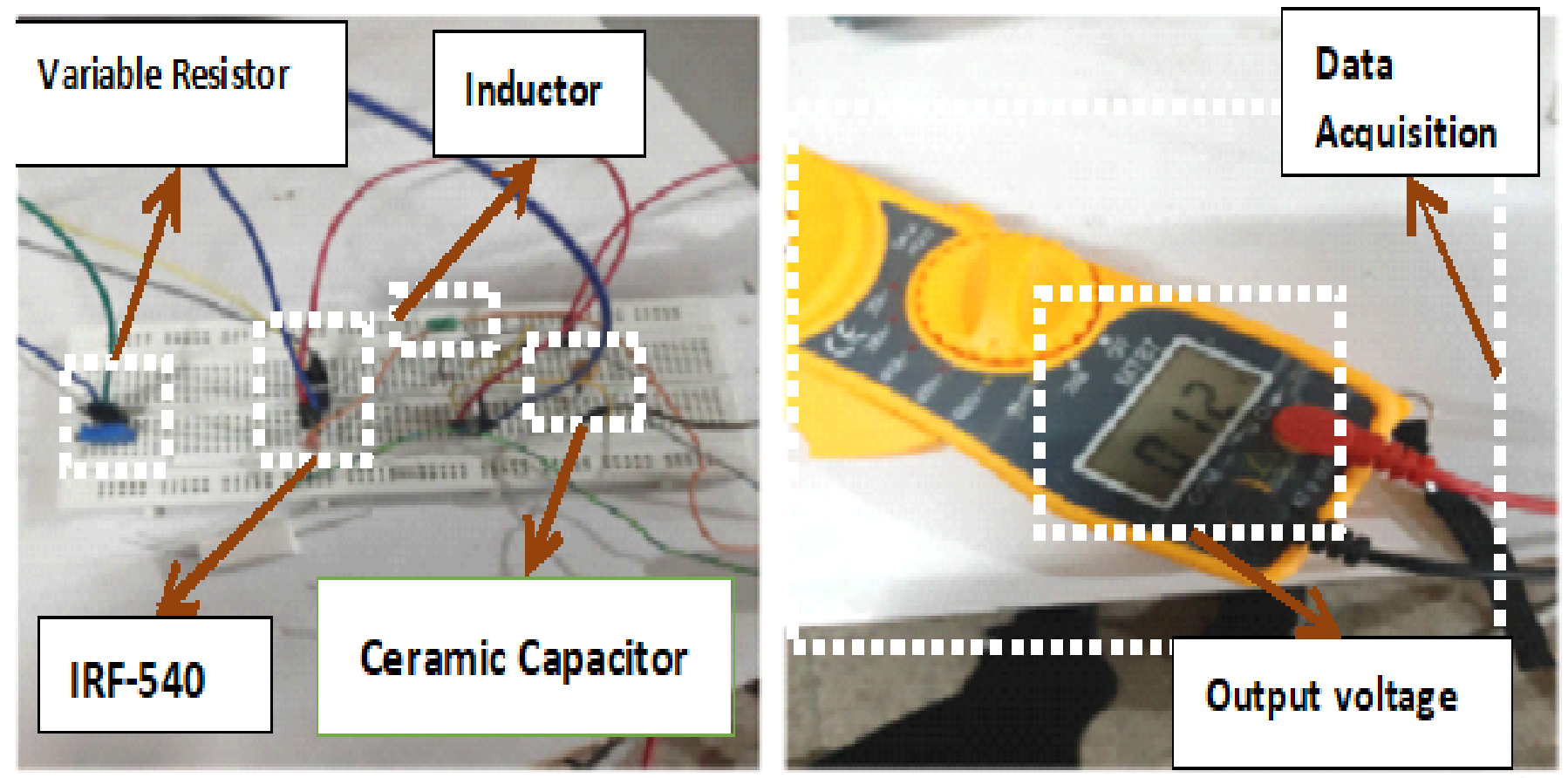

Fig. 12. Experimental Setup of Boost Converter

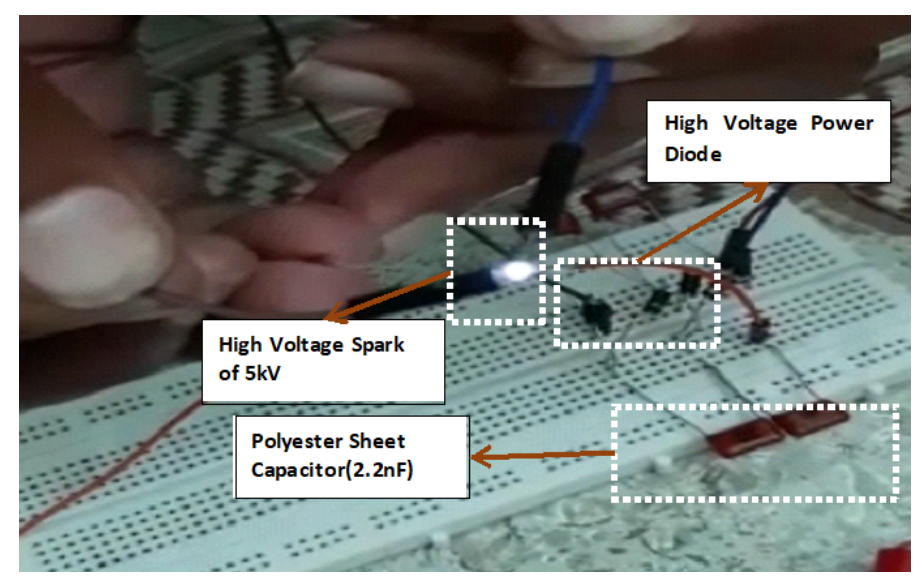

Fig. 13. CWM Design using Polyester Capacitor

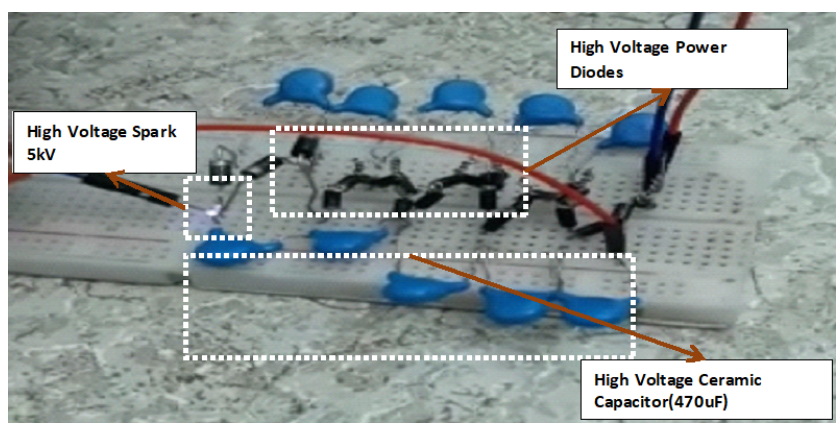

Fig. 14. CWM Design using Ceramic Capacitor

[6] Whitney, Donald, and Adam Toner. "High-voltage H-bridge control circuit for a lens driver of an electronic ophthalmic lens." U.S. Patent No. 10,216,009. 26 Feb. 2019.
[7] Tamuri, A. R., Bidin, N., \& Daud, Y. M. (2010). High voltage power supply for electro-optics applications. International Journal of Research, 3(2), 148-158. Retrieved 6 14, 2020, from http://arpapress.com/volumes/vol3issue2/ijrras_3_2_03.pdf

[8] Su Yi, Tu Liming, Sheng Hele et aL Protection Performance Study and Parameter Selection When Current Transformer Deeply Saturated[J]. Automation of Electric Power Systems, 2010, 34 (19):00-04.

[9] Transformer-based AC/DC converters, https://learn.adafruit.com/powersupplies/transformer-based-ac-dc-converters.

[10] Basic electronics, United States. Bureau of Naval Personnel, ISBN-13: 978-0-486-21076-6, pp. 40-53.

[11] K. I. Hwu, C. F. Chuang, and W. C. Tu, "High Voltage-Boosting Converters Based on Bootstrap Capacitors and Boost Inductors" IEEE Trans. On Industrial Elec., Vol., 60 No 6, June 2013.

[12] M. Pahlevani, S. Pan, S. Eren, A. Bakhshai and P. Jain, "An Adaptive Nonlinear Current Observer for Boost PFC AC/DC Converters," in IEEE Transactions on Industrial Electronics, vol. 61, no. 12, pp. 6720-6729, Dec. 2014, doi: 10.1109/TIE.2014.2316216

[13] Kumar, S. Senthil, et al. "CASCADE COCKCROFT-WALTON VOLTAGE MULTIPLIER APPLIED TO TRANSFORMERLESS HIGH STEP-UP DC-DC CONVERTER." Mathematical \& Computational Forestry \& Natural Resource Sciences 11.1 (2019).

[14] Bhonde, Krunal, et al. "Design, Simulation and Implementation of Generation of High DC Voltage by using Cockcroft Walton Multiplier." (2017).

[15] Vadnerkar, Sarang, Ullas Pazhayaveetil, and Eric J. King. "Boost converter with forced continuous conduction mode." U.S. Patent Application No. $15 / 432,150$.

[16] Ko, Hyun Jae. Analysis of boost converter in continuous conduction mode and discontinuous conduction mode. Diss. 2018.

[17] Lopez-Santos, Oswaldo, et al. "A single-phase transformer-based cascaded asymmetric multilevel inverter with balanced power distribution." IEEE Access 7 (2019): 98182-98196.

[18] Azmi, Nor A., et al. "5V to 6kV DC-DC Converter Using Switching Regulator with Cockcroft-Walton Voltage Multiplier for High Voltage Power Supply Module.” Recent Advances in Electrical \& Electronic Engineering (Formerly Recent Patents on Electrical \& Electronic Engineering) 12.2 (2019): 162-171. 
[19] Mudeng, Vicky, et al. "Design of Five Stages Cockroft-Walton with Passive Filter." 2019 6th International Conference on Electric Vehicular Technology (ICEVT). IEEE, 2019.

[20] Siddique, Md Mohasin. "Design and Implementation of an AC to High DC Voltage Generation Circuit Using Voltage Multiplier." (2019).

[21] Patel, Akul P., and Mulav Rathod. "Design, Simulation and Construction of Cockroft Walton Voltage Multiplier." Journals-Global Research and Development Journal of Engineering 1.4 (2016): 67-71.

[22] Azmi, N. A., et al. "Design of DC high voltage and low current power supply using Cockroft-Walton (CW) voltage multiplier." 2016 3rd International Conference on Electronic Design (ICED). IEEE, 2016.

[23] Prechtl, Johannes, Julian Kunze, Sophie Nalbach, Stefan Seelecke, and
Gianluca Rizzello. "Soft robotic module actuated by silicone-based rolled dielectric elastomer actuators: modeling and simulation." In Electroactive Polymer Actuators and Devices (EAPAD) XXII, vol. 11375, p. 113752C. International Society for Optics and Photonics, 2020.

[24] Pniak, Lucas, Morgan Almanza, Yoan Civet, and Yves Perriard. "Ultra High Voltage Switch for Bidirectional DC-DC Converter Driving Dielectric Elastomer Actuator." IEEE Transactions on Power Electronics (2020).

[25] Botha, Ingrid R., Glen Bright, and James ET Collins. "Evaluation of Dielectric Elastomers in Applications as Low Cost, SmallScale Actuators." In 2020 International SAUPEC/RobMech/PRASA Conference, pp. 1-6. IEEE, 2020. 